DE93 002995

\title{
SELECTION OF NON-ADSORBING ALKALI COMPONENTS
}

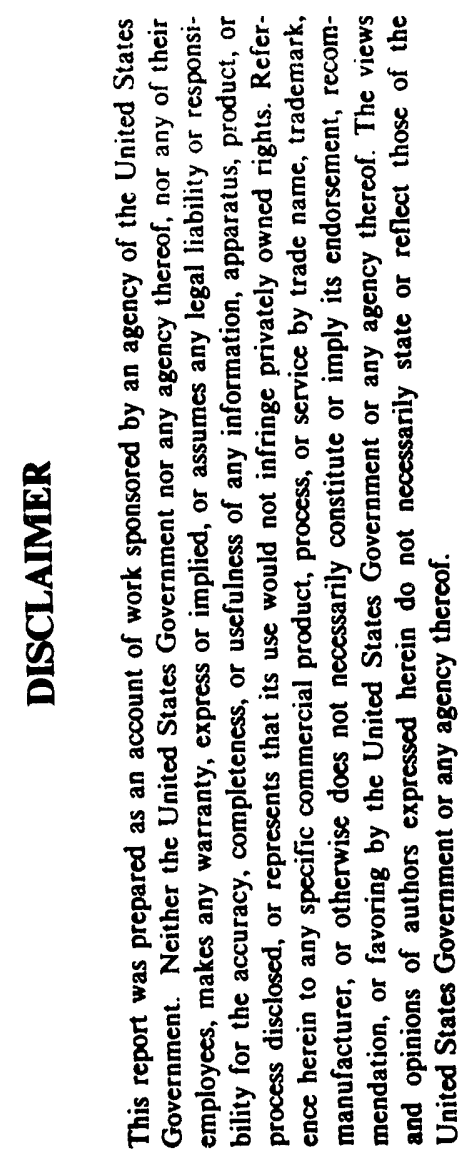

To be presented at:

\author{
Sheldon H.D. Lee \\ K. Natesan \\ and
William M. Swift \\ and
William M. Swift
}

\author{
Argonne National Laboratory \\ Chemical Technology Division \\ 9700 S. Cass Avenue \\ Argonne, IL 60439
}

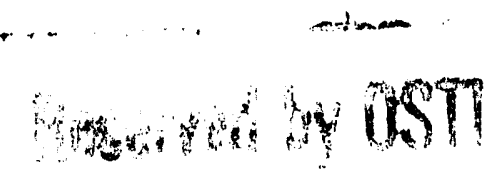

iviv 101992

DOE/METC 12th Annual Gasification and Gas Stream Cleanup Systems Contractor's Review Meeting, Morgantown, WV, September 15.17, 1992

The submitted manuxcript has been authored
by contractor of the U. S. Government
under contrect No. W.31-109ENG-38.
Accordinglv. the U. S. Government retains a
nonexclusive, rovalty-froe license to publish
or reproduce the published form of this
contribution, of allow others to do so. for
$U$. S. Government purposes.




\section{Selection of Non-Adsorbing Alkall Components}

CONTRACT INFORMATION

Contract Number

Contractor

Contract Project Manager

Principal Investigators

METC Project Manager

Perlod of Performance

Schedule and Milestones
ANL 49704 (AA-15-10-05)

Argonne National Laboratory

9700 South Cass Avenue

Argonne, IL 60439

Dr. David K. Schmalzer

Dr. Martin J. Steindler

Dr. Sheldon H. D. Lee

Dr. K. Natesan

Dr. William Swift

Dr. Kamalendu Das

April 1, 1992 to September 30, 1992

FY 92 Program Schedule

$S O N D J F M A M J J A S$

TGA Setup

Preparation of Candidate Material

Atmospheric Screening in PFBC

Environment

\section{OBJECTIVES}

The principal objective of this work is to identify metallic material(s) that will not adsorb alkali vapors for use in alkali sampling lines and/or process component materials for advanced coal utilization systems. Also being sought are a better understanding of the alkali adsorption mechanism of metallic materials and their behavior under combustion off-gas and gasification fuel gas environments.

\section{BACKGROUND INFORMATION}

This project supports the DOE/METC Fossil Energy Program for the development of advanced coal utilization systems, such as direct coal-fired turbine (DCFT), pressurized fluidized-bed combustion (PFBC), and integrated gasification combined-cycle (IGCC) systems. The alkali metal compounds present in the coal combustion off-gas and the coal gasification fuel gas (such as chlorides, hydroxides, and sulfates 
of sodium and potassium) are known to cause "hot corrosion" of hightemperature/high-pressure (HTHP) fire-side

They also have deleterious effects on many process components, such as valves, piping, filters, and separation membranes. Therefore, the ability to measure alkali levels in advanced coal utilization systems is a critical need.

In recent years, a real-time, on-line Ames alkali analyzer [3] and a fiber optic alkali analyzer [4] have been widely used in the field. Both analyzers require an HTHP sampling line to extract a representative sample of the process gas stream for alkali analysis. Our eartier work demonstrated that the accuracy of these analyzers for PFBC off-gas is distorted due to the significant capture of the alkali vapor by the HTHP stainless steel sampling line [5]. The mechanism of this alkali-vapor capture by the sampling line is not known. For successful operation of these analyzers, a suitable HTHP sampling line is needed.

\section{PROJECT DESCRIPTION}

This project consists of three phases of laboratory experimental study. In phase I (screening), eight candidate materials, 304SS (serves as a base material for comparison), Hastelloy C-276, Hastelloy $X$, Haynes No. 188, Allonized 304SS, Pt-coated 304SS, and ceramic-coated 304SS, will be subjected to atmospheric TGA study under the simulated PFBC (oxidizing) environment with and without alkali vapor doping. Each candidate material will be evaluated for its resistance toward alkali-vapor capture. In addition, a post-test metallographic characterization of the sample will be performed to obtain a better understanding of the alkali capture mechanism and material behavior. The material(s) with little or no alkali-vapor adsorption will be selected as the promising material(s) for the Phase II study.
In Phase II, the promising material(s) will be further tested in the TGA under elevated pressure to simulate the PFBC environment (in terms of temperature, pressure, and gas composition). The effect of pressure on the extent of alkali-vapor adsorption will be evaluated, and the test samples will be metallographically characterized. The most promising candidate material(s) will be identified and recommended for further testing in the actual PFBC environment.

In Phase III, four materials will be selected from the eight candidate materials screened in the PFBC environment and will be evaluated for their alkali-vapor capture by atmospheric TGA under the coal gasification fuel gas (reducing) environment. The tested samples will also be metallographically characterized. The most promising material(s) will be identified and recommended for further testing in the actual coal gasification environment.

\section{RESULTS}

\section{Literature Review on Alkall on Process Materials}

A literature review was conducted to obtain some background information about the effect of alkali on metallic process materials. Corrosion of structural materials exposed to PFBC effluent can occur because of either gas-phase oxidation/sulfidation or liquid-phase corrosion induced by an alkali deposit. The latter is an accelerated type of attack on materials, influenced by the vaporization and condensation of small amounts of impurities (such as sodium, potassium, chlorine, and sulfur, or their compounds) that are present in the coal feedstock. Corrosion of metallic materials in the presence of liquid sodium sulfate, either by itself or in combination with sodium chloride, has been a problem in gas turbines. This corrosion process has been termed "hot corrosion" to differentiate it from gas-phase sulfidation attack. Two types of 
hot corrosion have been identified: Type I, operative at $800-950^{\circ} \mathrm{C}$, and Type II, operative at $600-750^{\circ} \mathrm{C}$.

Type I hot corrosion can be split into an initiation (or incubation) stage and a propagation stage. The process, in general, requires the presence of liquid sodium sulfate (melting point $884^{\circ} \mathrm{C}$ ) on the metal surface. In the initiation stage, the protective oxide scale dissolves by a basic fluxing mechanism, and the corrosion rates are generally low. In the propagation stage, with the protective oxide having been destroyed and not able to re-form, the alloy is subjected to sulfidation by inward diffusion of sulfur, leading to accelerated corrosion rates.

Type II hot corrosion, also known as low-temperature hot corrosion, involves the eutectics of base metal sulfates and sodium sulfate and, therefore, occurs predominantly at lower temperatures, especially in the effluent of the $F B I$ environment. For example, the eutectic temperature for sodium sulfate-cobalt sulfate is $565^{\circ} \mathrm{C}$. In this case, the transient oxides of cobalt or nickel (which nucleate in the early stage of oxidation in chromium- and aluminum-containing superalloys) react with sodium sulfate to form eutectic salts that prevent formation of protective chromia or alumina. The corrosion process strongly depends on the partial pressure of sulfur trioxide at the melt/scale interface, but the process occurs at much lower temperatures than the melting point of sodium sulfate.

Extensive studies have been conducted to evaluate the hot corrosion behavior of nickel-base superalloys and coatings in environments typical of gas turbines [6-8]. The major thrust in these studies is to correlate the corrosion behavior of the alloys with parameters such as test temperature, salt $\left(\mathrm{Na}_{2} \mathrm{SO}_{4}\right)$ chemistry, salt film thickness, gas composition, and alloying element additions. The presence of $\mathrm{NaCl}$ in the environment can lead to $\mathrm{Na}_{2} \mathrm{SO}_{4}$ formation by the reaction:

$$
2 \mathrm{NaCl}+\mathrm{SO}_{3}+1 / 2 \mathrm{O}_{2}=\mathrm{Na}_{2} \mathrm{SO}_{4}+\mathrm{Cl}_{2}
$$

The sodium sulfate can contribute to hot corrosion. In general, high chromium alloys exhibit better resistance to hot corrosion. In addition to chromium, elements such as aluminum, titanium, and tungsten seem to impart better resistance. Elements such as molybdenum and carbon have a deleterious effect on the corrosion resistance.

Even though extensive studies have been conducted on hot-corrosion resistance of nickel-base superalloys, very little is known on the performance of iron-base heat resistance alloys. Some corrosion studies have been conducted on iron-base materials in the presence of synthetic coal ash with additions of $\mathrm{Na}_{2} \mathrm{SO}_{4}$ and/or $\mathrm{K}_{2} \mathrm{SO}_{4}$, in support of materials evaluation for superheaters and reheaters of coal-fired boilers [9]. The results, based on 100-h tests in a simulated combustion atmosphere with synthetic coal ash deposits, showed increased corrosion resistance with an increase in chromium content of the alloys up to $20-25$ wt $\%$.

Many institutions have attempted to quantify the alkali vapor in PFBC effluent. An Ames on-line, real-time alkali analyzer has been extensively tested at Argonne National Laboratory to measure the concentration of alkali ( $\mathrm{Na}$ and $\mathrm{K}$ ) vapor in PFBC effluent. In these measurements, Type 304 stainless steel tubing with $0.64-\mathrm{cm}$ dia (1/4-in. dia) was used as a sampling line to extract PFBC effluent for alkali-vapor analysis. In the early phase of calibrating and testing this analyzer with $\mathrm{NaCl}$ vapor, some of the $\mathrm{NaCl}$ vapor in the heated $\left(>700^{\circ} \mathrm{C}\right)$ stainless steel sampling line was lost [10]. To further study this phenomenon, Type 304 stainless steel tubing at high temperature $\left(840-950^{\circ} \mathrm{C}\right)$ and high pressure (9.2 atm absolute) was exposed to a nitrogen gas stream with and without $\mathrm{NaCl} / \mathrm{KCl}$ vapor and to a simulated PFBC effluent (containing, on the average, $3.3 \%$ $\mathrm{O}_{2}, 0.14 \% \mathrm{H}_{2} \mathrm{O}$ vapor, $540 \mathrm{ppmV} \mathrm{SO}$, alkali 
vapors, and the balance $\mathrm{N}_{2}$ ). Figure 1 schematically shows the experimental setup. Typical results from these tests are shown in Fig. 2 [5].

Figure 2 clearly shows that, after having been exposed for $3 \mathrm{~h}$ to a nitrogen gas stream containing 400-2200 ppbW sodium (as $\mathrm{NaCl}$ vapor) and 400-1500 ppbW potassium (as $\mathrm{KCl}$ vapor), the heated stainless steel line continuously released both $\mathrm{Na}$ and $\mathrm{K}$ into the alkali-vapor-free $\mathrm{N}_{2}$ gas stream in the ranges of $45-50 \mathrm{ppbW}$ sodium and 25-30 ppbW potassium. The amounts of alkali released from the line quickly increased to the ranges of 220-280 ppbW sodium and 180-240 ppbW potassium when the nitrogen stream was switched to an alkali-vapor-free simulated PFBC off-gas stream. Similar results were observed when the line was exposed to a simulated PFBC off-gas with and without $\mathrm{NaCl} / \mathrm{KCl}$ vapor. The results verified the previous observation that heated stainless steel captures $\mathrm{NaCl}$ and $\mathrm{KCl}$ vapors when exposed to the $\mathrm{NaCl}$ $\mathrm{KCl}$-vapor-bearing gas stream. Also, the captured alkalis were reversibly released to an alkali-vapor-free gas stream. However, the mechanism of the alkali vapor capture by, and release from, the heated stainless steel tubing was not determined.

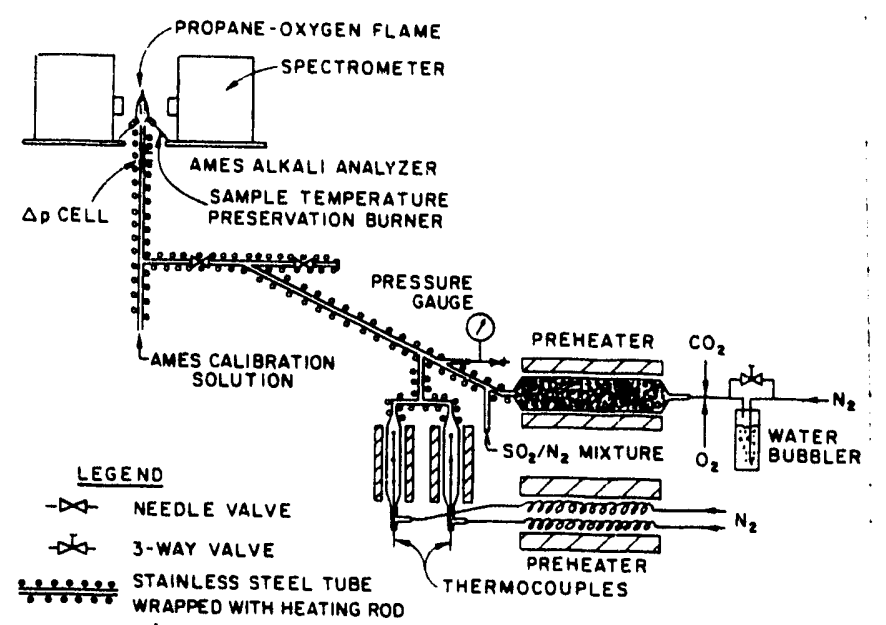

Fig. 1. Schematic of Pressurized NaClKCl-Vapor Generation Unit Integrated with Ames On-LIne, Real-Time Alkall Analyzer

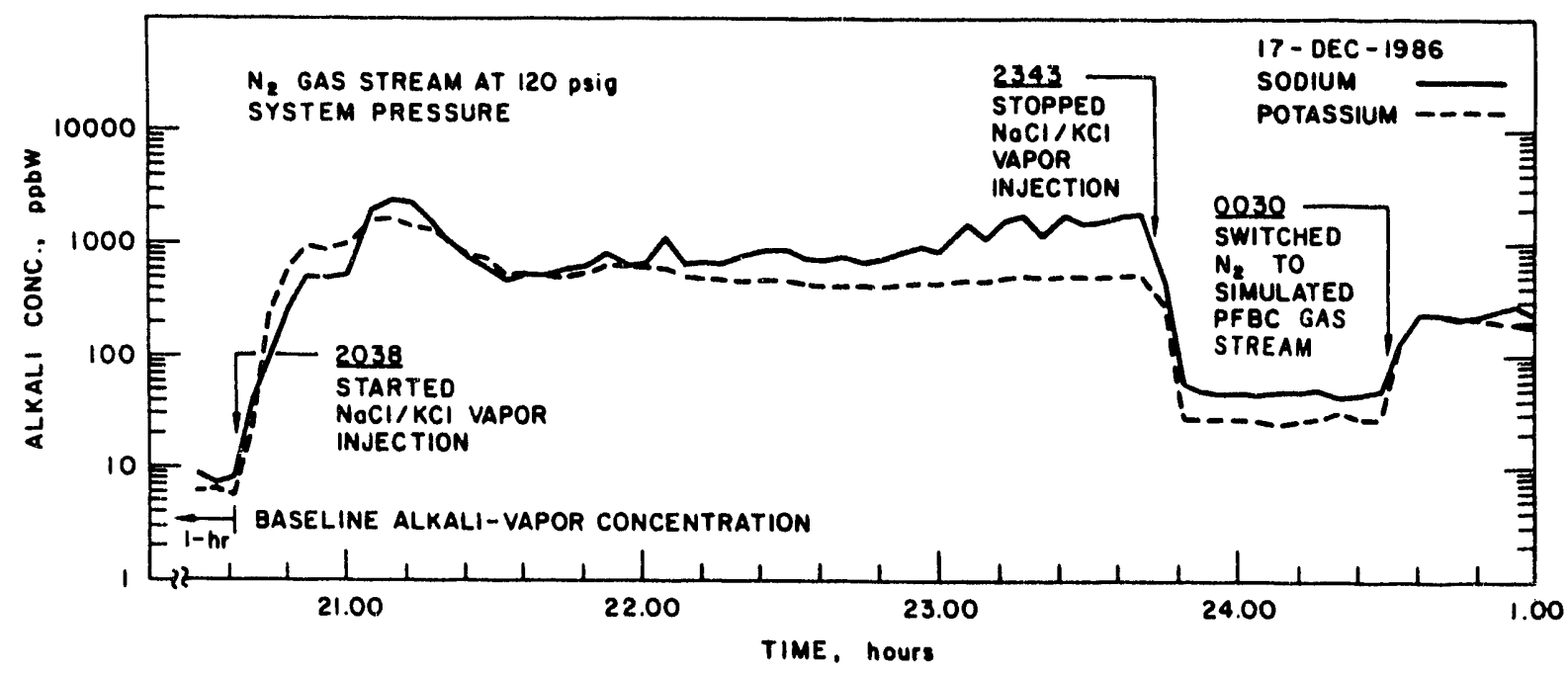

Fig. 2. Measured Sodium and Potasslum Concentrations In the Gas Stream for the Test of Type 304 Stainless Steel Sampling Line at $840-950^{\circ} \mathrm{C}$ and $9.2 \mathrm{~atm}$ Absolute 
At this stage, a suitable sampling line material (with little or no alkali-vapor capture capability) is not available. It is needed to identify metallic material(s) that will not capture alkali vapors and, therefore, can be used as the sampling line for the on-line alkali analyzer. The materials(s) may also be suitable for use as construction materials for other process components in advanced coal utilization systems.

\section{TGA Evaluation of Candidate Materlals}

The TGA setup for experimental evaluation of candidate materials is shown schematically in Fig. 3. With this setup, a candidate coupon sample is suspended in the TGA apparatus and heated to a selected temperature by a three-zone tubular furnace.

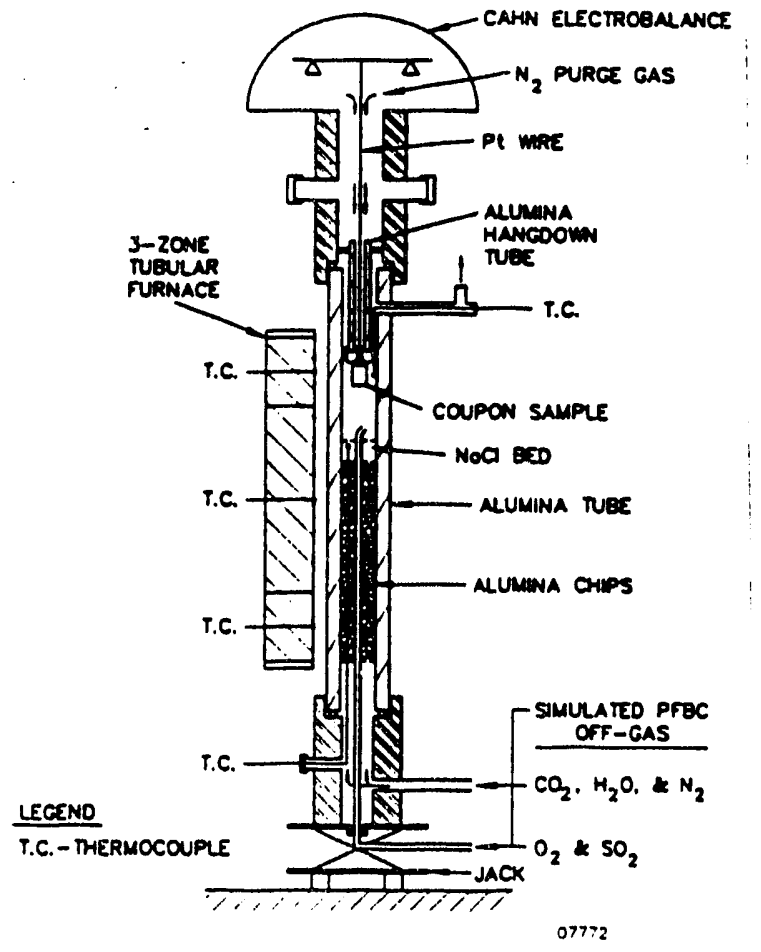

Fig. 3. TGA Setup for Studying AlkallVapor Capture of Metallic Materials

The $\mathrm{NaCl}$ vapor is generated from a $\mathrm{NaCl}$ bed and is carried upward to the coupon sample by preheated simulated PFBC offgas, which is introduced into the TGA apparatus from the bottom of the $\mathrm{Al}_{2} \mathrm{O}_{3}$ reactor tube. A packed bed of $\mathrm{Al}_{2} \mathrm{O}_{3}$ chips serves as a heat-transfer medium. To prevent vapor condensation on the $\mathrm{Pt}$ suspension wire on which the coupon sample is suspended, a downflow of nitrogen purge gas is introduced into the TGA apparatus. The temperatures of the coupon sample and the $\mathrm{NaCl}$ bed are monitored by thermocouples.

Coupon samples have been prepared for candidate materials of 304SS, Hastelloy C-276, Hastelloy X, and Haynes No. 188. The dimensions of these samples are 1.27$\mathrm{cm}(1 / 2-\mathrm{in}$.$) width, 2.54-\mathrm{cm}$ (1-in.) length, and $0.127-\mathrm{cm}(0.05-\mathrm{in}$.) thickness. Testing of these samples under the PFBC environment $\left(850-900^{\circ} \mathrm{C}\right.$ and simulated PFBC off-gas) is underway.

\section{FUTURE WORK}

The TGA testing of candidate materials will be continued in the oxidizing environment of PFBC and will be initiated in the reducing environment of coal gasification. The most promising candidate material(s) will be identified and recommended for future testing in the actual field environments.

\section{REFERENCES}

1. Reid, W. T. 1971. External Corrosion Deposits--Boilers and Gas Turbines, New York: American Elsevier Publishing.

2. Lunt, H. H. 1977. Hot Corrosion in Gas Turbine. ASME paper 77-WAVI-3.

3. Haas, W. J., D. E. Eckels,

R. N. Knisely, and V. A. Fassel. 1981. Development of Alkali and Trace Heavy Metal Monitors. In Proceedings of the DOE Contractors' Meeting on High Temperature, High Pressure Particulate and Alkali Control in Coal Combustion Process Streams, Morgantown, WV, pp. 599-620. 
4. Hensel, J. P., D. R. Goff, R. G. Logan, R. Pineault, R. R. Romanosky, Jr., and J. K. Wackter. 1987. On-Line, Real-Time Alkali Monitor for Process Stream Analysis. Rev. Sci. Instrum. 58 (9): 1647-1659.

5. Lee, S. H. D. and E. L. Carls. 1989. Measurement of Alkali Metal Vapors and Their Removal from a PressurizedFluidized-Bed Combustor Process Stream; Annual Report for October 1986-September 1987. ANL/FE-88-4. Argonne, IL: Argonne National Laboratory.

6. Stringer, J. 1977. Hot Corrosion of High Temperature Alloys. Ann. Rev. Mater. Sci. 7: 477.

7. Goebel, J. A., F. S. Pettit, and G. W. Goward. 1973. Mechanisms for the Hot Corrosion of Ni-Base Alloys. Met. Trans. 4: 261-283.

8. Luthra, K. L. and D. A. Shores. 1980. Mechanism of $\mathrm{Na}_{2} \mathrm{SO}_{4}$ Induced Corrosion at $600^{\circ}-900^{\circ} \mathrm{C}$. J.

Electrochem. Soc. 127: 2202-2210.

9. Kihara, S., and K. Nakagawa. 1989. Laboratory Coal Ash Corrosion Test. EPRI GS-6449. Palo Alto, CA: Electric Power Research Institute.

10. Lee, S. H. D., R. F. Henry, S. D. Smith, W. I. Wilson, and K. M. Myles. 1986. Alkali Metal Vapor Removal from Pressurized Fluidized-Bed Combustor Flue Gas: Annual Report for October 1985. ANL/FE-86-7. Argonne, IL: Argonne National Laboratory. 

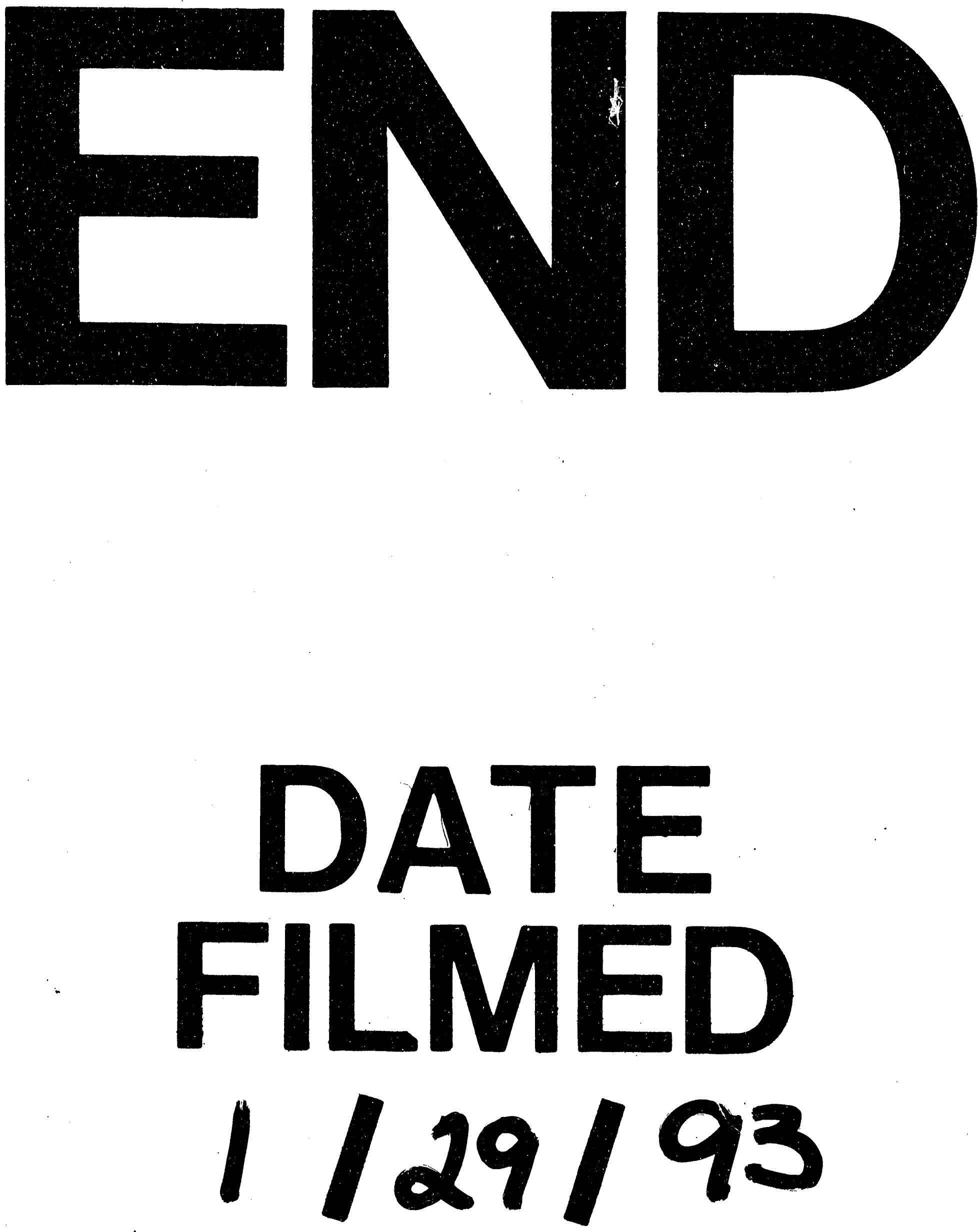
